\title{
Mitral Subvalvular Apparatus Intervention In Patients With Obstructive Hypertrophic Cardiomyopathy: does it need?
}

\author{
A Bogachev-Prokophiev", S Zheleznev, M Fomenko, A Pivkin, A Afanasiev, R Sharifulin, A Karaskov \\ From World Society of Cardiothoracic Surgeons 25th Anniversary Congress, Edinburgh \\ Edinburgh, UK. 19-22 September 2015
}

\section{Background/Introduction}

Systolic anterior motion (SAM) and mitral regurgitation (MR) in patients with hypertrophic obstructive cardiomyopathy $(\mathrm{HOCM})$ is associated with: Venturi effect and small LV cavity. According 2011 ACCF/AHA guideline extended myoectomy is gold standard in treatment patients with HOCM, however mitral subvalvular apparatus (MSA) intervention is still unclear.

\section{Aims/Objectives}

The purpose of this randomize study was assessment MSA intervention during extended septal myectomy in patient with HOCM and moderate to severe MR.

\section{Method}

Between 2010 and 2014, 182 patients underwent of extended myectomy procedures. 70 patient met inclusion criteria: were randomly assigned to receive MSA intervention in addition to septal myectomy (MSI group; $\mathrm{n}=36$ ) or undergo septal myectomy only (without MSI group; $\mathrm{n}=34$ ). A primary HOCM was the main indication for surgery according to 2011 ACCF/AHA guidelines. Mean age was $52.8 \pm 14.2$ years (range 22 to 74 years). Mean peak gradient was $90.7 \pm 24.2 \mathrm{~mm} \mathrm{Hg}$. Mean thickness of interventricular septum was $26.1 \pm 4.3 \mathrm{~mm}$. SAM syndrome observed in all patients. MR: moderate - $42(60 \%)$ pts, severe 28 (40\%) pts.

\section{Results}

There were no early death. MSA intervention include: mobilization papillary muscle $36(100 \%)$ pts, secondary chords resected 36 (100\%) pts (from 2 to 6), longitudinal resection papillary muscles (papillary muscles more than $15 \mathrm{~mm}) 32(88.9 \%)$ pts and excision of abnormal papillary muscles $9(25.0 \%)$ pts. Residual $M R \leq 2+$ was $14.7 \%$ (5 pts) in group without MSA and nobody had in MSA group ( $\mathrm{p}=0.023$ ); residual SAM was $23.5 \%$ (8 pts) in group without MSA and only $1(2.7 \%)$ pts had in MSA group $(\mathrm{p}=0.01)$. Mean time cross clamping was $42.4 \pm$ $15.2 \mathrm{~min}$ (without MSA) and $56.4 \pm 20.8 \mathrm{~min}$ (MSA group) ( $\mathrm{p}=0.002)$. Peak LVOT gradient was $12.2 \pm$ $6.3 \mathrm{~mm} \mathrm{Hg}$ (without MSA) and $8.7 \pm 4.5 \mathrm{~mm} \mathrm{Hg}$ (MSA group) ( $\mathrm{p}=0.009)$.

\section{Discussion/Conclusion}

MSA intervention during septal myectomy in patients with HOMC and MR safe and effective procedure. Complex MSA intervention as in addition to septal myectomy allows more effective eliminate SAMsyndrome and MR.

Published: 16 December 2015

doi:10.1186/1749-8090-10-S1-A138

Cite this article as: Bogachev-Prokophiev et al:: Mitral Subvalvular Apparatus Intervention In Patients With Obstructive Hypertrophic Cardiomyopathy: does it need? Journal of Cardiothoracic Surgery 2015 10(Suppl 1):A138. 